\title{
INVESTIGATING THE GENDER DIVERSITY IN THE FIELD OF RESEARCH: A STUDY BASED ON EDITORIAL BOARDS OF JOURNALS FALLING IN ISI THOMSON REUTERS
}

\author{
Ambreen Noman ${ }^{1}$ \\ Institute of Business and Technology \\ Irfan Haider Shakri ${ }^{2}$ \\ Institute of Business and Technology \\ Muhammad Tariq ${ }^{3}$ \\ Institute of Business and Technology
}

\begin{abstract}
Purpose: This paper reviews the gender composition in the editorial boards of the journals falling in the ISI Thomson Reuters. The purpose of this research paper is to watch the gender diversity in the editorial boards and to explore the perception of gender biasness if any in the field of research

Methodology/Sample : The study design is mix of quantitative and qualitative methods. The performance of either Gender has been measured via quantitative technique such as Independent sample T Test, whereas, the probable presence of Gender biasness has been investigated via comparative study of qualitative methods. This study takes a sample of 200 journals falling in ISI Thomson Reuters.

Findings: It has been concluded that there is Gender inequality in Editorial Journals despite of the fact that gender does not have significant impact on the performance of the journals in terms of the total citations. The mean total citation of the male dominated editorial boards has been observed as equal to that of mean total citation of the female dominated editorial boards.

Practical Implications: Any perception of gender in-equality may create deplorable image in research field. Therefore, it is essential to encourage the gender equality as well as gender equity in the field of Research.
\end{abstract}

Key Words: Quality Journal, Gender inequality

* The material presented by the author does not necessarily portray the viewpoint of the editors and the management of the Institute of Business \& Technology (IBT)

1 Ambreen Noman

2 Irfan Haider Shakri

3 Muhammad Tariq

(C) IBT-JBS is published by the Institute of Business and Technology (IBT).

Main Ibrahim Hydri Road, Korangi Creek, Karachi-75190, Pakistan. 


\section{INTRODUCTION}

The objective of this research paper is to investigate whether the performance of a Journal is affected by the gender. This paper, initially investigates the gender composition in the Editorial Boards, and then the gender composition shall be evaluated for the position of chief-editor is gender inequality in the Editorial Boards of the journals. The gender inequality in Editorial Boards represents that any one gender has monopoly on the Editorial Boards. The editors in the selected Editorial Boards shall be classified gender wise so that the respective gender composition may be analyzed. The study comprised of one hundred Editorial Boards of the Journals belonging to various disciplines falling in ISI Thomson Reuters randomly selected. Further, it shall be investigated that whether the gender has any impact over the performance of the journals in terms of total citations. The objective of such performance analysis is to investigate whether the gender affects the core performance of an editorial board. Briefly, it shall be analyzed that whether the stereotypes that men in majority guarantees the superior performance of the editorial board or vice versa. Moreover, the gender composition for the position of chief-editor shall also be investigated for similar objective.

The design of this study is made on both quantitative and qualitative aspects. The relation of Performance of Journal with gender has been investigated via quantitative methods. The behavioral tendencies towards male and female have been measured via qualitative means.

\subsection{Problem Statement}

This study attempts to study the impact of gender over the performance of the journals in terms of total citations. The impact of gender shall be observed on the editorial board and on the position of chief-editor.

\subsection{Hypotheses of the study}

H1: There is no difference between journals dominated by male editors than the journals dominated by female editors in terms of total citations.

$\mathrm{H} 2$ : There is no difference between journals headed by male editors than the journals headed by female editors in terms of total citations

H3: Under representation of female in Editorial Board is due to biasness or Stereotyping attitude of male members

\section{LITERATURE REVIEWS}

The equal participation of both genders is, therefore, essential in board membership as well as authorship in almost every field of research. However, any perception of gender in-equality would create deplorable image in academic as well as research field. Any evidence regarding under representation or glass ceiling for women in such scholarly contribution would mean that there is blockage in the flow of knowledge coming from female-scholars. It is essential to remove such blockage in order to enhance 
Metz and Harzing (2009) concluded that the representation of female editors in the Editorial Boards related to management journals has not been increasing with satisfactory level. Addis and Villa (2003) have found that the editorial board composition of Italian Boards in the fields of Economics is very awful. The glass ceiling for female scholars may be visualized in Italian boards concerned for Economics. It was argued that out of 36, eleven boards contained no women at all. During 1970s there were no female editors in the Italian Editorial board in Economics.

However, there are some institutions which claim for gender equality in their institutions. Rubin (1990) has determined that there is relatively equal participation of female in Governance and Administrative work in American Society for Public Administration (ASPA). The female representation in ASPA has been increasing at $1 \%$ per year, whereas their authorship has been increasing at $1.5 \%$ since 1972 . However, she confessed that women's scholarly contribution has not been increasing with that proportion. No such literature could be found that supported the claim that men are superior in intellectual capacity terms than women. Toren (1993) had made research on the effect of presence of gender diversity in firms' board on the firms' performance. It was suggested that the presence of male or female as board member did not affect the firms' performance. Personal intelligence and relevant experience of the board members affect the overall firm's performance rather than their gender characteristics. Then, what might be the reason that women could not acquire equal score in the Editorial Boards. In addition, female also lose score in terms of publication of articles. The study of Poole, Bornholt and Summers (1997) provides that under-representation of female editors in the Editorial Boards of management journals would invite monopoly of male editors. Naturally, male reviewers would approve the articles of their own interest. There are great chances that male-editors might have quite different fields of interest than female-editors. For instance as discussed earlier, Carrington and Pratt (2003) concluded that female representation has significantly been observed towards their traditional fields of research such as Teaching, Nursing, Arts, Humanities and Social Science. While, male are more inclined towards technical fields of research (Lamp, 2007). In addition, the presence of biasness in editorial board cannot be ignored. The study found a considerable commonality between male and female in the nature of the professional academic work activities undertaken and that women appear to be more positively oriented towards teaching while men have tendency towards research. The academic profession was also gender segregated with women largely absent in many fields of science and Engineering

Successful women in the Editorial Boards can be their role models. The absence of noticeable presence of successful women in the Editorial Boards, performing as role models might affect the inflow of new female entrants. For instance, the young entrant would be motivated to work in ICT sector, if women presently working in ICT seem as successful. A converse perception would discourage new female entrants (Lamp, 2007).

Fish and Gibbons (1989) found that male-authors have published more articles than the female-authors. There were some proposed reasons expressing the lesser 
contribution of female-authors: mostly female have to perform the traditional duties such as mother and housewife, which requires their time and energy accompanied with it, the presence of biasness in the editorial board cannot be ignored.

Murrell, Frieze, and Frost (1991) concluded that men prefer the fields such as Engineering, Investment, Business and Finance, whereas women prefer the fields such as Nursing, Social Work, Child and Health Care. Women give preference to average working hours and facilities to balance their work-home life than remuneration. Jacobs and Steinberg (1990) concluded that men prefer their career in masculine occupation, which requires technical and analytical skills such as Engineering, Investment analyst etc.

While female usually chose their career in feminine professions such as that require social skills. Caspare (2007) found that men had high interest in managerial position at high pay, whereas women preferred jobs which offered flexibility. Besides, some studies highlighted the existence of stereotypes which differentiated the preference of jobs of men and women with respect to the required level of skills and efforts. The study of Alsop (2005) suggested that various stereotypes exist in some work place; most common of them is that men were highly analytical and therefore analytical fields such as Engineering are mostly men-dominated fields, whereas women were considered best at communication skills and therefore fields such as Teaching and Nursing were mostly female-dominated.

In addition to biasness, the other possible reason of female underrepresentation in both authorship and editorial board membership may be the existence of favoritism in the Editorial Boards. Medoff (2003) has conducted research on the subject of existence of favoritism in the Editorial Boards in Economics. It has been concluded with the critical evolution of six major journals in economics that the articles written by the authors having personal ties to the members of editorial board were of high quality than the author having no such connection with editors. One possible reason for this favoritism is that the Editorial Boards' members try to achieve high quality in their publications with least search cost to be incorporated.

\section{RESEARCH METHODOLOGY}

Sample Size: A sample of 200 journals from the journals of ISI Thomson Reuters has been selected including social science and natural science.

Method of Data Collection: All data for the research has been collected from the websites of the journals falling in ISI Thomson Reuters. The impact factors and citations have been taken from Journal Citation Report: 2013 by Thomson Reuters Technique for Analysis: For the purpose of quantitative analysis the data has been analyzed based on independent sample t-test. This test is used when means (average results) of the sample data is compared at two levels or groups. This test is applied using SPSS software. The qualitative or the third hypothesis shall be investigated via comparative study. 


\section{DATA ANALYSIS AND RESULTS 4.1 Gender Inequality}

The table 1 (see appendix) shows that out of a sample of 200 journals taken from ISI Thomson Reuters male editors have strong dominancy in editorial board of $73.5 \%$ of the total sample journals, whereas only $21 \%$ journals are dominated by female editors. Only $5.5 \%$ of the journals showed fairly equal representation of both male and female editors. Similarly, the position of Editor-in-Chief is also dominated by male. $76.5 \%$ of total sample is dominated by male; only $19 \%$ is headed by female. $4.5 \%$ expressed fairly equal participation.

\subsection{Testing the Quantitative Hypotheses}

The independent sample $t$ test has been applied to test the equality of mean of total citations between male dominated Editorial Boards of the journals and female dominated Editorial Boards of the journals and to test the equality of mean of total citations between the journals headed by male editors and the journals headed by female editors. The leven's test accepts the equality of variance as shown in Table 2 (refer to appendix), so the respective test for equality of means has been taken. Both the sig value $(0.890)$ and t-stats value $(0.139)$ are insignificant, the equality of mean in terms of total citation has been accepted. This suggests that mean of total citation in Editorial Boards where male editors are in majority is equal to the mean of total citation where female are in majority. Therefore, the hypothesis that there is no difference between the journals dominated by the male editors than the journals dominated by female editors in terms of total citations has been accepted.

The leven's test accepts the equality of variance as shown in table 2, so the respective test for equality of means has been taken. Both the sig value $(0.465)$ and tstats value (0.733) are insignificant; therefore, the equality of mean in terms of total citation has been accepted. This suggests that mean of total citations of the journals headed by male editors is equal to the mean of the total citations of the journals headed by female editors. Therefore, the hypothesis that there is no difference between the journals headed by male editors than the journals headed by female editors in terms of total citations has been accepted.

The first hypothesis (H1) that there is no difference between journals dominated by male editors than the journals dominated by female editors in terms of total citations has been accepted because the F-stats is less than 3.84. The second hypothesis (H2) that there is no difference between journals headed by male editors than the journals headed by female editors in terms of total citations has been accepted because the Fstats is less than 3.84 .

H3: Under representation of female in Editorial Board is due to biasness or Stereotyping attitude of male members. 
Research type work Medoff (2003) has conducted research on the subject of existence of favoritism in the Editorial Boards in Economics. It has been concluded with the critical evolution of six major journals in economics that the articles written by the authors having personal ties to the members of editorial board were of high quality than the author having no such connection with editors. Jagsi, Guancial, Worobey, Henault, Chang, Starr and Hylek, E. M. (2006) concluded for biasness for female authors in the research output as well as in the Editorial Boards. Taylor, Wright, Moghaddam and Lalonde (1990) concluded for gender discrimination in the various fields especially in the field of Research

\section{DISCUSSION AND CONCLUSION}

The findings provide that that gender does not have any effect over the performance of a journal in terms of its total citations. Whether editorial board of any journal is dominated by male-editors or female-editors the performance in terms of total citations showed equal mean performance. Similarly the mean performance in terms of total citations has been observed equal whether the editorial board of a journal is headed by male editor or female editor. The conclusion confirms the findings of Toren (1993) that the presence of male or female as board member does not affect the firms' performance. Toren (1993) further added that personal intelligence and relevant experience of the board members affect the overall firm's performance rather than their gender characteristics. In a sample of 200 journals, $73.5 \%$ male-editors dominate Editorial Boards of the journals. Further, the position of Head (or the Chief Editor) of a journal is also dominated by the male editors $(76.5 \%$ journals are headed by male editors). The findings of Metz and Harzing (2009) and that of Addis and Villa (2003) confirmed the existence of gender inequality with male-dominancy in the Editorial Boards of the journals.

It has been concluded that gender does not affect the performance of any editorial board or as Macdonald and Kam (2007) has found that presence of gender in the board of directors of a firm does not affect the performance of that firm. Then, what are the factors that cause this in-equality? The study further concludes that the under representation of female in Editorial Board is due to biasness or Stereotyping attitude of male members. Likewise some studies have suggested that elements of biasness and stereotype or even glass ceiling may exist for female in the research field for instance Medoff (2003) found that the existence of favoritism in the Editorial Boards in Economics. Addis and Villa (2003) have pointed out significant biasness during the entire period (by 1996) female presence was limited to 1-to- $2 \%$ for the position in high level boards. Fish and Gibbons (1989) gave one possible reason as those women have more domestic responsibilities than men; this may deprive them from equal participation in research

\section{REFERENCES}

Addis, E., \& Villa, P. (2003). The Editorial Boards of Italian Economics Journals: Women, Gender, and Social Networking. Feminist Economics, 9(1), 75-91. 
Carrington, K., \& Pratt, A. (2003). How Far Have We Come? Gender Disparities in the Australian Higher Education System. Department of the Parliamentary Library, 34. $54-57$

Caspare, R. (2007). Does Female Board Representation Influence Firm Performance? The Danish Evidence. Corporate Governance: An International Review , 15(2), 404-413.

Fish, M., \& Gibbons, J. D. (1989). A Comparison of the Publications of Female and Male Economists. The Journal of Economic Education , 20(1), 93-105.

Jacobs, J. A., \& Steinberg, R. J. (1990). Compensating Differentials and the MaleFemale Wage Gap: Evidence from the New York State Comparable Worth Study. Social Forces , 69(2), 439-468.

Jagsi, R., Guancial, E. A., Worobey, C. C., Henault, L. E., Chang, Y., Starr, R., ... \& Hylek, E. M. (2006). The "gender gap" in authorship of academic medical literature-a 35-year perspective. New England Journal of Medicine, 355(3), 281-287.

Lamp, W. J. (2007). Perceptions of gender balance of is journal. Communications of the Association for Information Systems, 20, 124-133.

Macdonald, S., \& Kam, J. (2007). Ring a Ring o' Roses: Quality Journals and Gamesmanship in Managemen Studies. Journal of Management Studies, 44, 640-655.

Medoff, M. H. (2003). Editorial Favoritism in Economics? Southern Economic Journal , 70 (2), 425-434.

Metz, I., \& Harzing, A. (2009). Gender diversity in Editorial Boards of management journals. Academy of Management Learning \& Education, 8, 540-557.

Murrell, A. J., Frieze, I. H., \& Frost, J. L. (1991). Aspiring to careers in male- and female-dominated professions: A study of black and white college women. Psychology of Women Quarterly, 15, 103-127.

Poole, M., Bornholt, L., \& Summers, F. (1997). An International Study of the Gendered Nature of Academic Work: Some Cross-Cultural exploration. Higher Education , 34 (3), 373-396.

Rubin, M. (1990). Women in ASPA: The Fifty-Year Climb toward Equality. Public Administration Review, 50 (2), 277-287.

Steinberg, R. (1990). Social Construction of Skill: Gender, Power and Comparable Worth. Work and Occupations , 17, 449-482. 
Taylor, D. M., Wright, S. C., Moghaddam, F. M., \& Lalonde, R. N. (1990). The personal/group discrimination discrepancy perceiving my group, but not myself, to be a target for discrimination. Personality and Social Psychology Bulletin, 16(2), 254-262.

Toren, N. (1993). The temporal dimension of gender inequality in academia. Higher Education , 25, 439-455.

\section{APPENDIX}

Table 1. Gender Inequality View

Gender diversity

\begin{tabular}{|l|l|l|c|l|}
\hline & \multicolumn{2}{|c|}{ Gender majority in editorial board } & \multicolumn{2}{c|}{ Journals headed by } \\
\cline { 2 - 5 } & Number of Journals & $\%$ & Number of Journals & $\%$ \\
\hline Equal & 11 & $5.50 \%$ & 9 & $4.50 \%$ \\
Female & 42 & $21.00 \%$ & 38 & $19.00 \%$ \\
Male & 147 & $73.50 \%$ & 153 & $76.50 \%$ \\
Total & 200 & $100.00 \%$ & 200 & $100.00 \%$ \\
\hline
\end{tabular}

Table 2.Gender and performance of the Journals

\begin{tabular}{|l|l|l|l|l|}
\hline & \multicolumn{2}{|l|}{$\begin{array}{l}\text { Levene's Test for Equality } \\
\text { of Variances }\end{array}$} & \multicolumn{2}{l|}{$\begin{array}{l}\text { t-test for equality } \\
\text { of means }\end{array}$} \\
\hline Hypothesis & F-stats & Sig value & T -stats Sig & value \\
\hline $\begin{array}{l}\text { H:1 dominancy in editorial } \\
\text { board and total citation }\end{array}$ & .372 & .543 & .139 & .890 \\
\hline H2: journal Head and total citation & 1.596. & 210 & .733 & .465 \\
\hline
\end{tabular}

